\title{
$R$ - $\alpha$-Lipoic Acid Action on Cell Redox Status, the Insulin Receptor, and Glucose Uptake in 3T3-L1 Adipocytes
}

\author{
Hadi Moini,* Oren Tirosh, † Young Chul Park, $\ddagger$ Kyung-J oo Cho, ${ }^{* 1}$ and Lester Packer*, $\neq^{, 2}$ \\ *Department of Molecular Pharmacology and Toxicology, School of Pharmacy, University of Southern California, Los \\ Angeles, California 90033; †I nstitute of Biochemistry, Faculty of Agricultural, Food and Environmental Quality Sciences, \\ The Hebrew University of J erusal em Rehovot 76100, I srael; and ‡Department of Molecular and Cell Biology, \\ University of California at Berkeley, Berkeley, California 94720-3200
}

Received September 13, 2001, and in revised form October 29, 2001; published online December 19, 2002

The insulin signaling pathway has been reported to mediate R- $\alpha$-lipoic acid- (R-LA-)-stimulated glucose uptake into 3T 3-L 1 adipocytes and L 6 myotubes. We investigated the role of the thiol antioxidant dihydrolipoic acid (DHLA) and intracellular glutathione (GSH) in RLA-stimulated glucose transport and explored the hypothesis that R-LA could increase glucose uptake into 3T 3-L 1 adipocytes in an oxidant-mimetic manner. R-LA pretreatment of 3T3-L1 cells stimulated glucose transport at early time points (30 min- $6 \mathrm{~h}$ ), whereas it inhibited glucose uptake at later time points. Analysis of the oxidized and reduced content of LA in cells and medium showed that $>90 \%$ of lipoic acid present was in its oxidized form. Furthermore, all oxidized forms of LA (S-, R-, and racemic LA) stimulated glucose uptake, whereas the reduced form, dihydrolipoic acid, was ineffective. I ntracellular GSH levels were not changed at the early time points (before $12 \mathrm{~h}$ ), while longer preincubation (24-48 h) of cells with R-LA significantly increased intracellular GSH. Pretreatment of adipocytes with R-LA increased intracellular peroxide levels at early time points (30 min- 6 h), after which it was decreased (12-48 h). R-LA also increased tyrosine phosphorylation of immunoprecipitated insulin receptors from 3T3-L1 adipocytes. These results indicate that (i) 3T 3-L 1 adipocytes have a low capacity to reduce R-LA and the oxidized form of lipoic acid is responsible for stimulating glucose uptake, (ii) R-LA modulates glucose uptake by changing the intracellular redox status, and (iii) the insulin receptor is a potential cellular target for R-LA action. () 2002 Elsevier Science

\footnotetext{
${ }^{1}$ On leave from Department of Biological Sciences, Korea Advanced Institute of Science and Technology, Kusong-Dong 373-1, Taejon, Korea, 305-171.

${ }^{2}$ To whom correspondence and reprint requests should be addressed. Fax: (510) 865-5431. E-mail: packerresearch@aol.com.
}

Key Words: $\alpha$-lipoic acid; intracellular redox state; insulin signaling; glucose transport.

$\alpha$-Lipoic acid $(\mathrm{LA})^{3}$ has been used in Germany for the relief of symptoms of diabetic neuropathy $(1,2)$. A growing body of evidence suggests that LA may have potential therapeutic value in lowering elevated glucose levels in diabetic conditions. Oral or intravenous administration of LA was shown to increase insulin sensitivity in individuals with type 2 diabetes (3-5). In animal models of diabetes, chronic LA administration increased GLUT-4 protein level in muscle membranes, improved insulin-stimulated 2-deoxyglucose uptake into isolated skeletal muscles, and reduced blood glucose level indicating that LA might enhance the capacity of insulin stimulated glucose transport and utilization in skeletal muscle (6-8). However, LA itself was also shown to enhance glucose uptake into epitrochlearis muscles isolated from both obese ( $\mathrm{fa} / \mathrm{fa}$ ) and lean (fa/ -) Zucker rats (9).

Mechanistic studies conducted in insulin responsive cells in culture demonstrated that LA rapidly stimulates glucose uptake by activating elements of the insulin signaling pathway $(10,11)$. Insulin action is initiated by insulin binding to the extracellular $\alpha$-subunit of the insulin receptor (IR), which transmits a transmembrane signal activating the intracellular tyrosine kinase domain of the $\beta$-subunits $(12,13)$. Following IR autophosphorylation, the tyrosine kinase domain of the $\beta$-subunit tyrosine phosphorylates a number of cel-

\footnotetext{
${ }^{3}$ Abbreviations used: DCF, dichlorofluorescein; DHLA, dihydrolipoic acid; GSH, reduced glutathione; IR, insulin receptor; LA, $\alpha$-lipoic acid; PI 3-kinase, type I phosphatidylinositol 3-kinase; TBH, tert-butyl hydroperoxide.
} 
lular proteins, including members of the insulin receptor substrate (IRS1/2/3/4) family (14). Engagement of the $\mathrm{SH} 2$ domains in the p85 regulatory subunit of type I phosphatidylinositol 3-kinase (PI 3-kinase) with tyrosine phosphorylated IRS serves to activate the cataIytic p110 subunit and to target the PI 3-kinase to its downstream effectors such as protein kinase B/Akt (15, 16). Activation of PI 3-kinase was shown to be necessary for insulin-stimulated translocation of glucose transporter-4 (GLUT4) from a sequestered intracellular pool to the plasma membrane $(17,18)$. Using $L 6$ myotubes and 3T3-L 1 adipocytes as a model of muscle and fat cells in culture, R-LA was shown to increase tyrosine phosphorylation of IR and IRS-1, to enhance PI 3-kinase and Aktl activities, to elevate GLUT4 content in the plasma membranes, and to increase glucose uptake into the cells $(19,20)$. Although these findings have substantially increased our understanding of LA action on the insulin signaling pathway, the basis for the ability of R-LA to activate the elements of this pathway, its mode of action and molecular target(s) are not yet known.

Intracellular redox status is known to play an important role in the modulation of insulin action. Treatment of IR-transfected Chinese hamster ovary cells with antioxidants such as $\mathrm{N}$-acetyl-cysteine or butylated hydroxyanisole inhibited insulin responsiveness, whereas partial inhibition of glutathione metabolism, which intracellularly induces a mild oxidative stress condition, stimulated IR tyrosine phosphorylation when measured in vitro (21). A similar increase in IR kinase activity was observed following cell treatment with hydrogen peroxide (22-25). Moreover, it has been found that oxidation of critical cysteine residues in the IR $\beta$-subunit may also result in an increase in its intrinsic tyrosine kinase activity, whereas low concentrations of dithiothreitol inactivates the IR kinase, supporting the importance of oxidation of critical thiol groups in activation of the insulin signaling pathway $(26,27)$. LA is known to be intracellularly reduced to the potent dithiol antioxidant, dihydrolipoic acid (DHLA), and to enhance intracellular reduced glutathione (GSH) levels in a variety of cells $(28,29)$. Based on its chemical structure, LA, an eight-carbon compound that contains a disulfide bond can also act as a mild oxidant molecule before its conversion to the re duced form. This study was undertaken to explore the hypothesis that R-LA increases glucose uptake into 3T3-L 1 adipocytes by an oxidant-mimetic manner.

\section{MATERIALS AND METHODS}

Chemicals. Glucose, dihydrolipoic acid, cytochalasin B, tert-butyl hydroperoxide, wortmannin, insulin, 3-isobutyl-1-methylxanthine, $2^{\prime}, 7^{\prime}$-dichlorodihydrofluorescin diacetate, and dexamethasone were purchased from Sigma Chemical Co. (St. Louis, MO). 2-[ $\left.{ }^{14} C(U)\right]-$ deoxy-D-glucose and $\left[\gamma^{-32} \mathrm{P}\right]$ ATP was obtained from NEN Life Science
Products (Boston, MA). Protein A/G agarose was from Calbiochem (San Diego, CA) Monoclonal anti-insulin receptor beta chain antibody (Insulin R $\beta$, 29B4) was from Santa Cruz Biotech Inc. (Santa Cruz, CA). 4G10 anti-phosphotyrosine antibody was from Upstate Biotechnology (Lake Placid, NY). Hybond ECL nitrocellulose membrane was from Amersham (Arlington Heights, IL). Cell culture reagents and other chemicals were purchased from $L$ ife Technologies (Gaithersburg, MD).

Cell culture 3T3-L1 preadipocytes (American Type Culture Collection) were grown to confluence in Dulbecco's modified Eagle medium (DMEM) containing 10\% FCS, 100 units $/ \mathrm{ml}$ of penicillin, and $100 \mu \mathrm{g} / \mathrm{ml}$ of streptomycin as previously described (30). Cells were induced to differentiate to adipocytes $48 \mathrm{~h}$ after confluence by changing the medium to complete DMEM supplemented with $5 \mu \mathrm{g} / \mathrm{ml}$ of insulin, $0.25 \mu \mathrm{M}$ of dexamethasone, and $0.5 \mathrm{mM}$ of 3-isobutyl-1methylxanthine for $72 \mathrm{~h}$. Cells were then maintained in DMEM containing $10 \%$ FCS and antibiotics and used 8-10 days after differentiation when more than $90 \%$ of cells exhibited the adipocyte phenotype.

2-Deoxygl ucose uptake. Uptake of 2-deoxyglucose by 3T3-L 1 adipocytes was measured as previously described (31). Briefly, cells were washed twice with phosphate-buffered saline containing 2.5

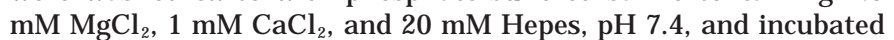
with test compounds in the same buffer at $37^{\circ} \mathrm{C}$. Transport assay was then initiated by addition of $2-\left[{ }^{14} \mathrm{C}(\mathrm{U})\right]$-deoxy-D-glucose $(25 \mu \mathrm{M} ; 10$ $\mu \mathrm{Ci} / \mathrm{ml}$ ) to each well for $10 \mathrm{~min}$ at $37^{\circ} \mathrm{C}$. In some experiments, glucose transport was measured after addition of a mixture of $2-\left[{ }^{14} \mathrm{C}(\mathrm{U})\right]-$ deoxy-D-glucose (10 $\mu \mathrm{M} ; 2 \mu \mathrm{Ci} / \mathrm{ml})$ and D-glucose (5 mM). Transport assay was terminated by addition and subsequent washing of cells with ice-cold PBS. Cells were lysed in $10 \%$ SDS or $50 \mathrm{mM} \mathrm{NaOH}$. The radioactivity was determined by scintillation counting of lysates extracted in SDS, whereas total protein was determined in lysates extracted in $\mathrm{NaOH}$ using the Bradford procedure (Bio-Rad Laboratories, Richmond, CA). Glucose uptake values were corrected for non-carrier-mediated transport by measuring glucose uptake in the presence of $10 \mu \mathrm{M}$ cytochalasin B.

Intracellular reactive oxygen species. Intracellular oxidants were detected using 2',7'-dichlorodihydrofluorescin diacetate $\left(\mathrm{H}_{2} \mathrm{DCF}\right.$ DA) (32). Briefly, cells seeded in 12-well plates were incubated for 2- $48 \mathrm{~h}$ with R-LA $(250 \mu \mathrm{M})$ and loaded with $\mathrm{H}_{2}$ DCF-DA $(20 \mu \mathrm{M})$ for the last 30 min in PBS containing R-LA. For some experiments cells were washed and incubated with $\mathrm{R}-\mathrm{LA}(0.25-1 \mathrm{mM})$ and $\mathrm{H}_{2} \mathrm{DCF}-\mathrm{DA}$ $(20 \mu \mathrm{M})$ for $30 \mathrm{~min}$. Following the treatments, cells were gently scraped by a lifter and suspended in the same media. For detection of intracellular fluorescence, cells were excited using a 488-nm argon-ion laser in a flow cytometer (XL, Coulter, FL). The dichlorofluorescein (DCF) emission was recorded at $530 \mathrm{~nm}$. Data were collected from at least 20,000 cells.

Intracellular glutathione. Cells seeded in 12-well plates were incubated with $250 \mu \mathrm{M}$ of R-LA for various times. Cells were then washed with ice-cold PBS, treated with $4 \%(\mathrm{w} / \mathrm{v}) \mathrm{m}$-phosphoric acid and scraped. All samples were immediately frozen in liquid nitrogen and stored at $-70^{\circ} \mathrm{C}$ until analysis by HPLC. I mmediately before the assay, samples were thawed, vortexed, and then centrifuged at $15,000 \mathrm{~g}$ for $2 \mathrm{~min}$ at $4^{\circ} \mathrm{C}$. The clear supernatant was removed and injected into the HPLC system. HPLC-EC detection of intracellular GSH was performed using an ESA coulometric detector (Chelmsford, MA) as described previously (33).

Quantitation of $\alpha$-lipoic acid and dihydrolipoic acid. Cells seeded in 12-well plate were incubated with $250 \mu \mathrm{M}$ of R-LA for various times. The media were collected. Cells were scraped from the wells and collected in $4 \% \mathrm{~m}$-phosphoric acid $(\mathrm{w} / \mathrm{v})$. The level of racemic LA and DHLA in the cell lysate and cell culture media were determined by HPLC using ESA coulometric detector (Chelmsford) as described (34). 

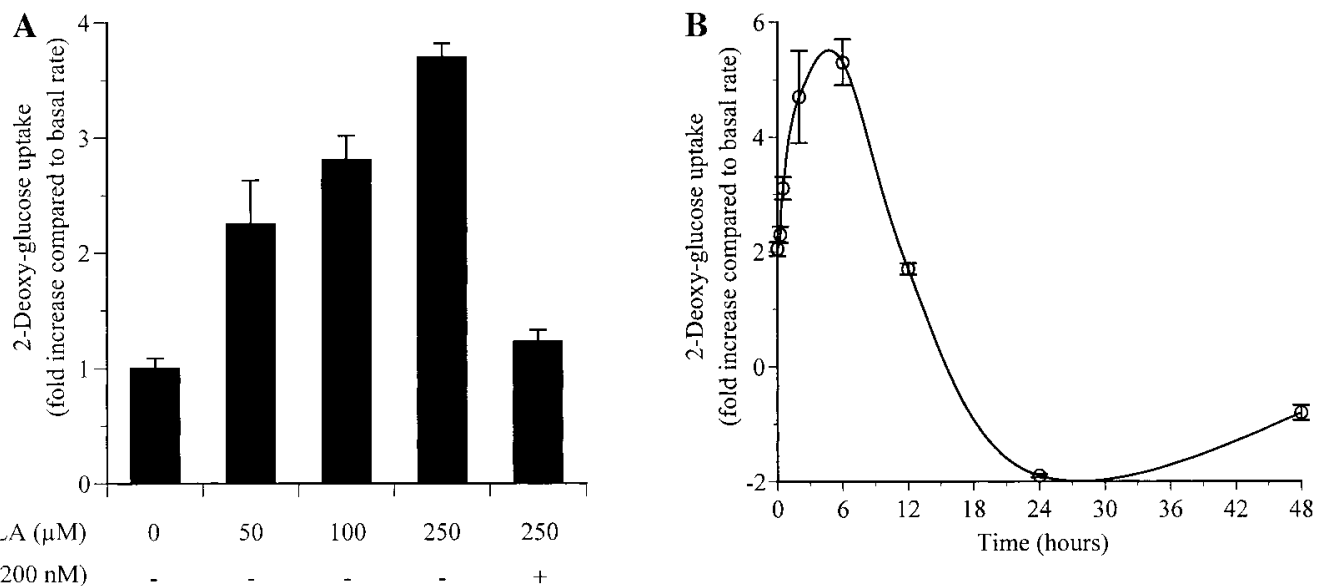

FIG. 1. Effect of R-LA on 2-deoxyglucose uptake in 3T3-L1 adipocytes. (A) Concentration dependence of R-LA action. Cells were preincubated with R-LA at indicated concentrations for $30 \mathrm{~min}$ before glucose transport assay. When present, wortmannin was added to cells 30 min prior to R-LA preincubation. (B) Time dependence of R-LA action. Cells were preincubated with $250 \mu M$ of R-LA for indicated times before glucose transport assay. Glucose uptake values were corrected for non-carrier-mediated transport by measuring glucose uptake in presence of $10 \mu \mathrm{M}$ cytochalasin B added just before start of transport assay and were expressed as fold increase compared to the basal rate.

Cell Iysis and IR immunoprecipitation. Cells in $\mathrm{T}_{75}$ flasks were serum deprived for $5 \mathrm{~h}$, washed three times with ice-cold PBS, and lysed in lysis buffer (50 mM Tris- $\mathrm{HCl}$ buffer, $\mathrm{pH} 7.2,150 \mathrm{mM} \mathrm{NaCl}$, $1 \%$ Nonidet P-40, $0.5 \%$ sodium deoxycholate, $0.1 \%$ SDS, $1 \mathrm{mM}$ EGTA, $25 \mathrm{mM} \mathrm{NaF}, 1 \mathrm{mM}$ sodium orthovanadate, $1 \mathrm{mM}$ PMSF, 5 $\mu \mathrm{g} / \mathrm{ml}$ leupeptin, and $2 \mu \mathrm{g} / \mathrm{ml}$ aprotinin). After centrifugation, the clear supernatant was incubated with $2 \mu \mathrm{g} / \mathrm{ml}$ of monoclonal antiinsulin receptor beta chain antibody (Insulin $\mathrm{R} \beta$, 29B4) overnight at $4^{\circ} \mathrm{C}$. The immune complexes were collected by incubating the sample with protein $A$ plus protein $G$ agarose for overnight at $4^{\circ} \mathrm{C}$. The immunoprecipitated insulin receptors were washed three times with lysis buffer and twice with phosphorylation buffer $(20 \mathrm{mM}$ Hepes, $\mathrm{pH}$ $7.2,100 \mathrm{mM} \mathrm{NaCl}, 5 \mathrm{mM} \mathrm{MgCl}, 5 \mathrm{mM} \mathrm{MnCl}$, and $100 \mu \mathrm{M}$ sodium orthovanadate).

In vitro kinase assay and detection of IR $\beta$-subunit phosphorylation. In vitro kinase assay was performed as previously described (21). Briefly, aliquots of immunoprecipitated insulin receptors were incubated, in the phosphorylation buffer, with $100 \mathrm{nM}$ insulin or 250 $\mu \mathrm{M} \mathrm{R}$ - or S-LA for $30 \mathrm{~min}$ at RT, and in vitro phosphorylation was conducted for $15 \mathrm{~min}$ at $30^{\circ} \mathrm{C}$ after adding $6.5 \mu \mathrm{Ci}\left[\gamma^{-32} \mathrm{P}\right] \mathrm{ATP}$. The reaction was stopped by boiling the samples in Laemmli sample buffer and proteins were separated by reducing SDS-PAGE. ${ }^{32} \mathrm{P}$ incorporation was then determined by autoradiography. To detect tyrosine phosphorylation of insulin receptor beta domain, the in vitro phosphorylation was performed by adding $1 \mathrm{mM}$ cold ATP for $20 \mathrm{~min}$ at $30^{\circ} \mathrm{C}$. The proteins were separated electrophoretically and transferred to Hybond ECL nitrocellulose membrane. The membrane was blocked in Blocker Casein in PBS (Pierce, IL), immunoblotted with monoclonal anti-phosphotyrosine antibody (4G10), and tyrosine phosphorylated $\beta$-subunit was detected using an $\mathrm{ECL}^{\text {plus }}$ kit (Amersham, NJ ).

Preparation of $\alpha$-lipoic acid isomers and dihydrolipoic acid. 50 $\mathrm{mM}$ stock solutions of R-LA, S-LA, and racemic LA were prepared in $20 \mathrm{mM}$ Hepes, pH 7.4. A $250 \mathrm{mM}$ stock solution of DHLA was prepared in DMSO. A matched volume of DMSO was added to the control cells when it was used as a solvent.

Data presentation. Data are reported as mean \pm SD of at least three independent experiments performed in triplicate. Comparison between multiple groups was made by analysis of variance (ANOVA) or two-tailed $z$ test. The minimum level of significance was set at $\mathrm{P}<$ 0.05 .

\section{RESULTS}

\section{Effect of R- $\alpha$-lipoic Acid on Glucose Transport}

In 3T3-L 1 adipocytes basal glucose transport was $1.46+0.19 \mathrm{pmol} / \mathrm{min} / \mathrm{mg}$ protein. Insulin (100 nM) stimulation increased glucose uptake into the cells by 4.6-fold (6.7 $\pm 0.30 \mathrm{pmol} / \mathrm{min} / \mathrm{mg}$ protein). Pretreatment of 3T3-L 1 adipocytes with R-LA for $30 \mathrm{~min}$ increased glucose transport dose dependently relative to the control cells at concentrations between 50-250 $\mu \mathrm{M}$ (Fig. 1A). Wortmannin, a PI-3-kinase inhibitor, inhibited R-LA-stimulated glucose uptake. Pretreatment with R-LA over $48 \mathrm{~h}$ exhibited a biphasic effect on glucose uptake into 3T 3-L 1 adipocytes (Fig. 1B). Addition of R-LA just before the start of the transport assay (0 time) increased glucose uptake by twofold. R-LA pretreatment increased glucose transport with a maximal 5.3-fold over basal rate obtained by $6 \mathrm{~h}$ preincubation. However, longer preincubation (24 or $48 \mathrm{~h}$ ) inhibited glucose uptake into 3T3-L1 adipocytes.

\section{Reduction of R-LA by 3T3-L1 Adipocytes}

The capacity of adipocytes to reduce R-LA and thereby to generate the strong antioxidant, DHLA, was evaluated following incubation with $250 \mu \mathrm{M}$ of $\mathrm{R}-\mathrm{LA}$ for various times (Table I). Following rapid extraction and snap injection into an HPLC-EC system $94.4 \%$ of added R-LA was found to be remain in the oxidized form after $6 \mathrm{~h}$ preincubation. The total amount of DHLA detected in cells and their supernatants at this time point was approximately $5.0 \%$ of the added R-LA. Lower amounts of both LA and DHLA was found in the cells and their supernatants after $48 \mathrm{~h}$ incubation with R-LA. 
TABLE I

Reduction of R-LA by 3T3-L1 Adipocytes

\begin{tabular}{|c|c|c|c|c|}
\hline & \multicolumn{2}{|c|}{$6 \mathrm{~h}$} & \multicolumn{2}{|c|}{$48 \mathrm{~h}$} \\
\hline & $\alpha$-Lipoic acid & Dihydrolipoic acid & $\alpha$-Lipoic acid & Dihydrolipoic acid \\
\hline Supernatant ( $\%$ of added LA) & $94.4 \pm 13.5$ & $4.9 \pm 0.91$ & $33.5 \pm 4.0$ & $1.4 \pm 0.55$ \\
\hline Cells (\% of added LA) & $0.56 \pm 0.19$ & $0.005 \pm 0.003$ & $0.3 \pm 0.07$ & $0.0005 \pm 0.001$ \\
\hline
\end{tabular}

Note Cells were incubated with $250 \mu \mathrm{M}$ of R-LA for 6 or $48 \mathrm{~h}$. The level of racemic LA and DHLA in cell lysates and supernatants was measured by HPLC and expressed as percentage of total added R-LA.

Effect of Stereoisomers of Lipoic Acid and

Dihydrolipoic Acid on Glucose Transport

The effect of oxidized stereoisomers of $\alpha$-lipoic acid, $R$ - and S-LA, their racemate mixture, racemic LA, and the reduced racemate form, DHLA, on glucose uptake was examined after 30 min preincubation of cells with $250 \mu \mathrm{M}$ of the either test compounds (Fig. 2). R-, S-, and racemic LA increased glucose transport by $4.1 \pm$ 1.6-, $3.1 \pm 1.3-$, and $5.0 \pm 0.9$-fold, respectively, over the basal rate. A significantly higher increase in glucose transport was obtained by racemic LA pretreatment compared to S-LA $(P<0.01)$. DHLA increased glucose uptake by $1.38 \pm 0.1$-fold over the basal rate. DHLA-induced glucose transport was significantly less than that el icited by the oxidized stereoi somers, R- and S-LA, and racemic LA $(P<0.001)$.

\section{Effect of R- $\alpha$-lipoic Acid on Intracellular GSH}

\section{Content}

The intracellular GSH content of 3T3-L 1 adipocytes was $3.2 \pm 0.20 \mathrm{nmol} / \mathrm{mg}$ protein. A statistically nonsig-

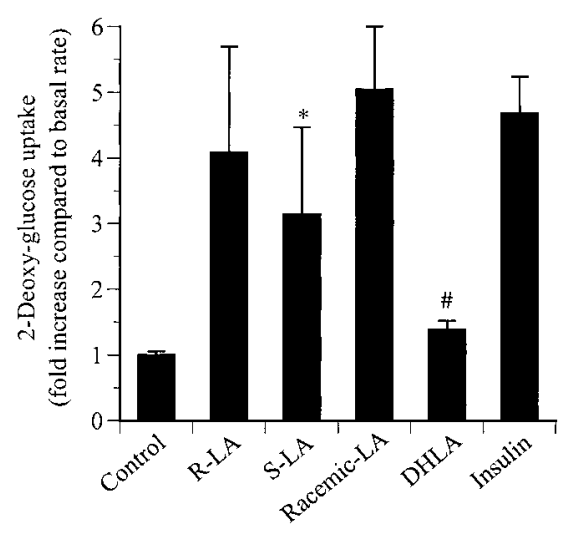

FIG. 2. Comparative effect of $\alpha$-lipoic acid stereoisomers and DHLA on glucose transport. 3T3-L 1 adipocytes were incubated with $250 \mu \mathrm{M}$ of R-LA, S-LA, racemic LA, or DHLA for $30 \mathrm{~min}$ before glucose transport assay. Insulin (100 nM) was added just before the start of glucose transport assay. The number of independent experiments performed in triplicate for R-LA, S-LA, racemic-LA, DHLA, and insulin-treated cells were $6,6,5,3$, and 3 , respectively. *Significantly different from racemic LA, $P<0.01$ (ANOVA). \#Significantly different from S-, R-, and racemic LA, $\mathrm{P}<0.001$ (ANOVA). nificant elevation in intracellular GSH level was observed after $12 \mathrm{~h}$ incubation of cells with $250 \mu \mathrm{M}$ of R-LA (Fig. 3). However, preincubation of cells with R-LA for 24 or $48 \mathrm{~h}$ significantly increased, as compared to the basal, the intracellular level of GSH to $7.0 \pm 0.47$ and $9.5 \pm 2.41 \mathrm{nmol} / \mathrm{mg}$ protein, respectively $(\mathrm{P}<0.05)$. No change was detected in intracellular GSH levels after incubation with R-LA $(250 \mu \mathrm{M})$ for 0.5-2 h (not shown).

Tert-Butyl Hydroperoxide (TBH) Acutely Stimulates Glucose Transport

Pretreatment with the strong oxidant TBH for 30 min dose dependently increased glucose uptake into 3T3-L 1 adipocytes (F ig. 4). Similar to R-LA, the TBHstimulated glucose uptake was completely abrogated with wortmannin, the PI 3-kinase inhibitor.

\section{R- $\alpha$-lipoic Acid I ncreases I ntracellular Oxidant Levels}

Intracellular DCF fluorescence was determined after incubation of 3T3-L 1 adipocytes with R-LA at various concentrations and time points. R-LA pretreatment

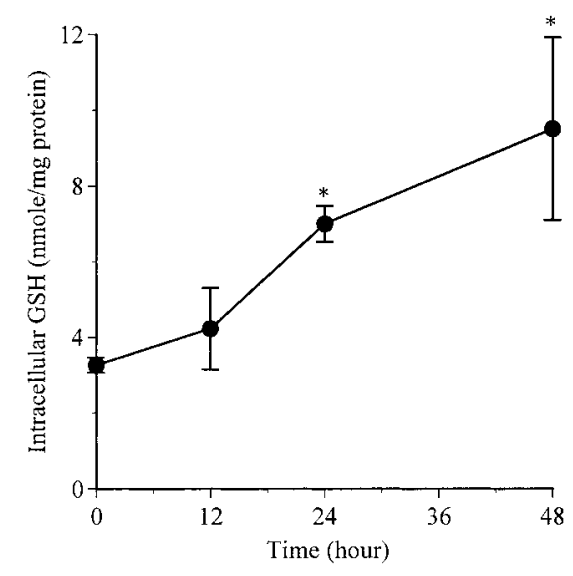

FIG. 3. Effect of R-LA on intracellular GSH content. 3T3-L1 adipocytes were incubated with $250 \mu \mathrm{M}$ of R-LA for indicated times and intracellular GSH was measured by HPLC as described under Materials and Methods. *Significantly different from 0 time, $\mathrm{P}<0.05$ (ANOVA). 


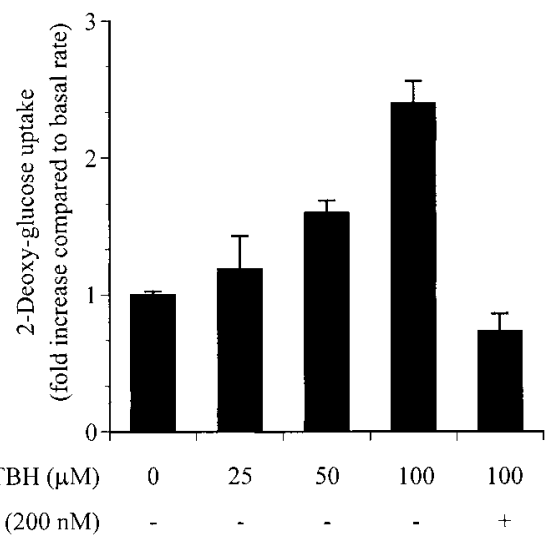

FIG. 4. TBH increases glucose uptake into 3T3-L 1 adipocytes. Cells were preincubated with indicated concentrations of $\mathrm{TBH}$ in the presence and absence of wortmannin $(200 \mathrm{nM})$ for $30 \mathrm{~min}$ at $37^{\circ} \mathrm{C}$ before glucose transport assay.

increased $\mathrm{H}_{2}$ DCF oxidation as estimated by the ele vated DCF fluorescence (F ig. 5A). To evaluate whether the increase in intracellular oxidant level by R-LA is superimposed with the temporal kinetics of glucose uptake, a second experiment was performed in which cells were incubated with $250 \mu \mathrm{M}$ R-LA over $48 \mathrm{~h}$. The DCF signal was at a maximum following a 6-h preincubation of cells with R-LA (Fig. 5B).

\section{R- $\alpha$-lipoic Acid Facilitates Insulin Receptor Autophosphorylation}

The direct effect of $\mathrm{R}$ - and S-LA on insulin receptor activation was analyzed by measuring its kinase activity in vitro. Preincubation of immunoprecipitated IR with insulin for 30 min strongly increased autophosphorylation of the IR $\beta$-subunit (Fig. 6). R-LA (250 $\mu \mathrm{M})$ pretreatment of immunoprecipitated IR for $30 \mathrm{~min}$ in- creased ${ }^{32} \mathrm{P}$ incorporation into and tyrosine phosphorylation of IR $\beta$-subunit to a comparable degree as insulin-treated immunoprecipitated IR. However, a relatively weaker phosphotyrosine signal, as compared to insulin or R-LA, was observed after treatment of immunoprecipitated IR with S-LA.

\section{DISCUSSION}

$\alpha$-Lipoic acid has been the focus of intensive research in the last few years $(28,29)$. The oxidized form is reduced by the multienzyme $\alpha$-keto acid dehydrogenase complexes resulting in formation of the potent dithiol antioxidant, DHLA (35). The oxidized form has also been proposed to function as an antioxidant due to its ability to react with number of reactive oxygen species in vitro $(28,29)$. However, our results point to the fact that the oxidized form of LA activates the insulin signal transduction pathway by acting as a pro-oxidant.

3T3-L 1 Adipocytes Possess a Low Capacity to Reduce

$\mathrm{R}$ - $\alpha$-lipoic Acid and the Oxidized I soforms Are

Effective in Stimulating Glucose Transport

Pretreatment of cells with R-LA for times as brief as $10 \mathrm{~min}$ was found to stimulate glucose transport into 3T3-L 1 adipocytes. In agreement with Klip et al. (11, 19), wortmannin, a relatively specific inhibitor of $\mathrm{PI}$ 3-kinase, abrogated the ability of R-LA to stimulate glucose transport indicating that PI 3-kinase mediates the stimulation of glucose transport by R-LA. However, in spite of the reported millimolar amounts used in these studies $(11,19)$, our investigations show that the concentration of R-LA required to stimulate glucose transport is in the micromolar range, which is comparable with its plasma level after intravenous or oral
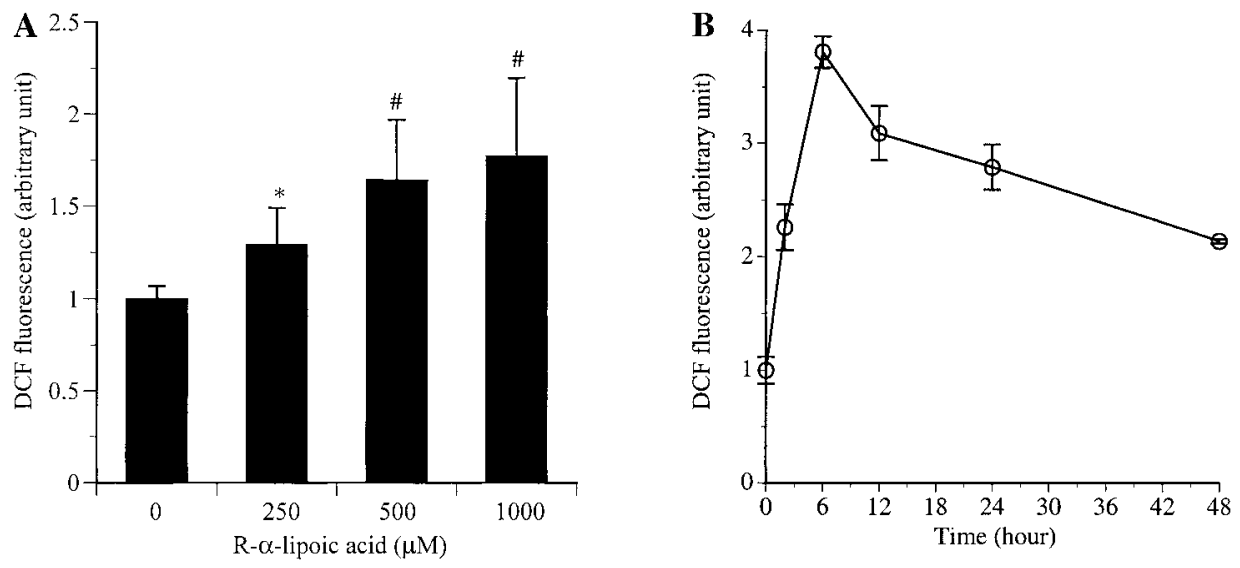

FIG. 5. Effect of R-LA on intracellular level of oxidants in 3T3-L 1 adipocytes. Cells were preincubated with indicated concentrations of R-LA for $30 \mathrm{~min}(\mathrm{~A})$ or with $250 \mu \mathrm{M}$ R-LA for various times (B). Flow cytometric measurement of DCF fluorescence was determined as described in Materials and Methods. $y$-Axes represent DCF fluorescence emission recorded in a 4-decade log scale. $* P<0.05$ and $\# P<0.01$ compared with control ( $\mathrm{z}$ test, two-tailed). 


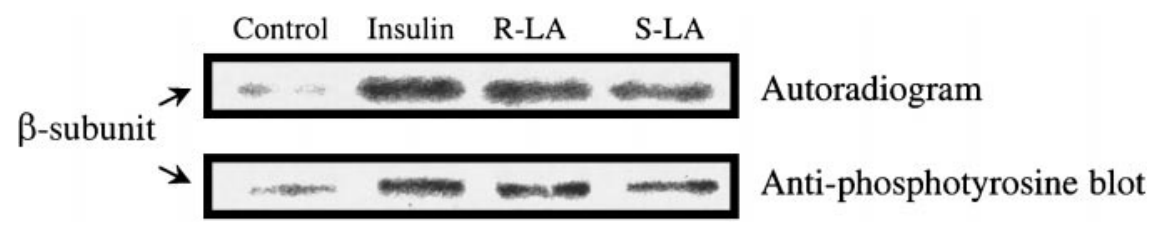

FIG. 6. R- and S-LA facilitate insulin receptor autophosphorylation in vitro. Immunoprecipitated IR was incubated with $250 \mu \mathrm{M}$ of R- or $\mathrm{S}-\mathrm{LA}$ or with $100 \mathrm{nM}$ of insulin for $30 \mathrm{~min}$ and then subjected to in vitro kinase assay in the presence of either ATP or $\gamma^{32}{ }^{32}$-ATP. Proteins were separated by SDS-PAGE. ${ }^{32} \mathrm{P}$ incorporation was determined by autoradiography (upper panel). Tyrosine phosphorylation was analyzed with the monoclonal phosphotyrosine antibody $4 \mathrm{G} 10$ by ECL (lower panel). A representative bl ot of three independent experiments is shown.

administration of $200-600 \mathrm{mg}$ of $\operatorname{LA}(36,37)$. R-LA was shown to be more potent than the $\mathrm{S}$ isoform in its ability to improve insulin-stimulated glucose uptake in skel etal muscles from obese Zucker rats or to stimulate glucose transport in L 6 myotubes and 3T3-L 1 adipocytes $(7,11,19)$. In the present study, although S-LAstimulated glucose uptake was lower than that elicited by $R-L A$, it did not reach significance, whereas racemic LA was found significantly more effective than S-LA.

Analysis of cellular and extracellular levels of LA and DHLA showed that after $6 \mathrm{~h}$ preincubation the majority (>90\%) of LA was present in the oxidized form. Lower amounts of LA and DHLA in both cells and their supernatants were detected after $48 \mathrm{~h}$ incubation with R-LA, which might be due to cellular metabolism. Furthermore, when added exogenously, DHLA was far less effective in stimulating glucose transport than the oxidized isoforms. A slight increase in glucose transport observed upon stimulation with DHLA might likely be due to the LA generated from the spontaneous oxidation of DHLA in the aqueous medium. Taken together, these findings show that the oxidized isoforms, R- and S-LA, or their racemic mixtures, but not the reduced form, are effective in stimulating glucose uptake into 3T3-L1 adipocytes.

\section{R- $\alpha$-lipoic Acid Modulates Glucose Transport by Changing Intracellular Redox Status}

Intracellular GSH level was unchanged by preincubation of 3T3-L 1 adipocytes with R-LA for up to $12 \mathrm{~h}$, demonstrating that alterations in GSH levels are not involved in R-LA-stimulated glucose uptake observed at earlier time points. The fact that DHLA is not also implicated in R-LA action and only the oxidized isoforms are effective in stimulating glucose transport implies that R-LA, an eight-carbon compound with a functional disulfide group in the dithiolane ring, likely acts as a pro-oxidant. The pro-oxidant effect of $L A$ was clearly demonstrated using $\mathrm{H}_{2}$ DCF-DA, which is an indicator of intracellular oxidant levels (38-40). DCF fluorescence measurements showed that treatment with R-LA increased intracellular oxidant levels, which reached their maximal level at $6 \mathrm{~h}$. TBH, a well-known oxidant, also increased DCF fluorescence (data not shown) and stimulated glucose transport in a wortmannin sensitive manner, indicating that the insulin signaling pathway is oxidant sensitive. Indeed, hydrogen peroxide was hypothesized to act as a second messenger for the observed effects of insulin (41). Recently, human fat cells were shown to possess a multireceptor-linked, plasma membrane-bound $\mathrm{H}_{2} \mathrm{O}_{2}$ generating system that is under antagonistic control by a large and diverse group of hormones, including insulin, the $\beta$-adrenergic agonist isoproterenol, and different isoforms of fibroblast and platelet-derived growth factors, providing further evidence in support of a second messenger function for oxidants such as hydrogen peroxide (42-46).

The maximal intracellular level of oxidants was observed after $6 \mathrm{~h}$ pretreatment of 3T3-L 1 with R-LA, a finding that is consistent with the kinetics of the R-LAstimulated elevations of glucose transport. However, longer incubation ( $>12 \mathrm{~h}$ ) of cells with R-LA significantly increased cellular GSH levels while at the same time points the intracellular level of oxidants and glucose transport rate were decreased. Hence, a parallel behavior was observed between the intracellular oxidant level, GSH level, and R-LA-stimulated glucose uptake, suggesting that at the early time points (up to 6 h) R-LA likely increases glucose transport by changing the intracellular redox status toward an oxidizing condition whereas at later time points R-LA, by increasing the intracellular GSH content, shifts the intracellular environment toward more reducing conditions, which lowers the rate of glucose transport.

It should be emphasized that whether the observed elevation in GSH level upon treatment with R-LA is due to an improvement in the utilization of cysteine (47), an adaptive response, or is mediated by another mechanism warrants further investigation. However, the amount of R-LA reduced to DHLA seems to be adequate to reflect the changes in the redox status of sensitive cellular proteins when cell volume is taken into account. Given the fact that mammalian cells are 10-30 $\mu \mathrm{m}$ in diameter (corresponding to an average inner volume of approximately $7 \times 10^{-9} \mathrm{ml}$ ), the total concentration of DHLA formed under our experimental 
condition by reduction of $4.9 \%$ of the added R-LA was calculated as $5.0 \mathrm{mM}$.

\section{Insulin Receptor as a Target of R-LA Action}

The mechanism by which R-LA and oxidants such as hydrogen peroxide or pervanadate exert insulin-like effects in cells is not known. Although this effect might partly be due to inhibition of protein tyrosine phosphatases, which are sensitive to inactivation by oxidants $(48,49)$, several lines of evidence suggests that the functional activity of the insulin receptor can be also modulated by alteration of redox state of the cysteine residues present in IR $\alpha$ - and $\beta$-subunits $(26,27,50)$. When incubated with immunoprecipitated IR, R-LA increased tyrosine phosphorylation of IR, indicating that R-LA facilitates IR autophosphorylation. Consistent with the stimulation of glucose transport, S-LA was found to be less effective in facilitating IR autophosphorylation. The basis for relatively lower efficacy of S-LA observed in this and previous studies $(7,11,19)$ is not known. Since sodium orthovanadate, a potent inhibitor of protein tyrosine phosphatases, was present in the phosphorylation buffer, the observed effect of LA on IR autophosphorylation is not due to the oxidative inactivation of protein tyrosine phosphatases, which might be brought down during the immunoprecipitation of IR. However, whether the observed effect of R-LA on IR autophosphorylation is due to oxidation of the cysteine residues present in the $\beta$-subunit and whether disulfides other than LA are able to facilitate IR autophosphorylation remain to be elucidated.

Taking into consideration that pharmacokinetic studies have shown a relatively short half-life (30 min) for $L A(36)$, our results favor the hypothesis that $R-L A$ may activate the insulin signaling pathway in insulin responsive tissues, which possess a low capacity to reduce $L A$ such as adipose tissue by increasing intracellular oxidant levels and/or directly activating IR.

\section{ACKNOWLEDGMENTS}

This research was funded by a grant (\#011868) from the American Diabetes Association. The authors thank Dr. Nava Bashan for advice on differentiating adipocyte cells in culture.

\section{REFERENCES}

1. Ziegler, D., Reljanovic, M., Mehnert, H., and Gries, F. A. (1999) Exp. Clin. Endocrinol. Diabetes 107, 421- 430.

2. Ziegler, D., Schatz, H., Conrad, F., Gries, F. A., Ulrich, H., and Reichel, G. (1997) Diabetes Care 20, 369-373.

3. J acob, S., Henriksen, E. J ., Schiemann, A. L., Simon, I., Clancy, D. E., Tritschler, H. J ., J ung, W. I., Augustin, H. J ., and Dietze, G. J . (1995) Arzneimittelforschung 45, 872- 874.

4. J acob, S., Henriksen, E.J ., Tritschler, H. J ., Augustin, H. J ., and Dietze, G. J . (1996) Exp. Clin. Endocrinol. Diabetes 104, 284288.
5. J acob, S., Ruus, P., Hermann, R., Tritschler, H. J ., Maerker, E., Renn, W., Augustin, H. J ., Dietze, G. J ., and Rett, K. (1999) Fre Rad. Biol. Med. 27, 309-314.

6. J acob, S., Streeper, R. S., Fogt, D. L., Hokama, J . Y., Tritschler H. J., Dietze G. J ., and Henriksen, E. J . (1996) Diabetes 45, 1024-1029.

7. Streeper, R. S., Henriksen, E. J ., J acob, S., Hokama, J . Y., Fogt, D. L., and Tritschler, H. J . (1997) Am. J . Physiol. 273, E 185E191.

8. Khamaisi, M., Potashnik, R., Tirosh, A., Demshchak, E., Rudich, A., Tritschler, H. J ., Wessel, K., and Bashan, N. (1997) Metabolism 46, 763-768.

9. Henriksen, E. J ., J acob, S., Streeper, R. S., F ogt, D. L., Hokama, J . Y., and Tritschler, H. J . (1997) Life Sci. 61, 805- 812.

10. Ramath, S., Tritschler, H. J ., and Eckel, J . (1999) Horm. Metab. Res. 31, 632- 635.

11. Estrada, D. E., Ewart, H. S., Tsakiridis, T., Volchuk, A., Ramlal, T., Tritschler, H., and Klip, A. (1996) Diabetes 45, 1798-1804.

12. Frattali, A. L., Treadway, J . L., and Pessin, J . E. (1992) J . Biol. Chem. 267, 19521-19528.

13. Luo, R. Z., Benia, D. R., Fernandes, A., Yip, C. C., and Ottensmeye, F. P. (1999) Science 285, 1077-1080.

14. White, M. F. (1998) Mol. Cell. Biochem. 182, 3-11.

15. Ueki, K., Yamamoto-Honda, R., Kaburagi, Y., Yamauchi, T., Tobe, K., Burgering, B. M., Coffer, P. J ., Komuro, I., Akanuma, Y., Yazaki, Y., and Kadowaki, T. (1998) J. Biol. Chem. 273, 5315-5322.

16. Kohn, A. D., Summers, S. A., Birnbaum, M. J ., and Roth, R. A. (1996) J . Biol. Chem. 271, 31372-31378.

17. Yonezawa, K., Ueda, H., Hara, K., Nishida, K., Ando, A., Chavanieu, A., Matsuba, H., Shii, K., Yokono, K., and Fukui, Y. (1992) J . Biol. Chem. 267, 25958-25965.

18. Czech, M. P., and Corvera, S. (1999) J . Biol. Chem. 274, 18651868.

19. Yaworsky, K., Somwar, R., Ramlal, T., Tritschler, H. J ., and Klip, A. (2000) Diabetologia. 43, 294-303.

20. Konrad, D., Somwar, R., Sweeney, G., Yaworsky, K., Hayashi, M., Ramlal, T., and Klip, A. (2001) Diabets 50, 1464-1471.

21. Schmid, E., El Benna, J., Galter, D., Klein, G., and Droge, W. (1998) Faseb J . 12, 863-870.

22. Hayes, G. R., and Lockwood, D. H. (1987) Proc. Natl. Acad. Sci. USA 84, 8115- 8119.

23. Kadota, S., Fantus, I. G., Deragon, G., Guyda, H. J ., and Posner, B. I. (1987) J . Biol. Chem. 262, 8252-8256.

24. Koshio, O., Akanuma, Y., and Kasuga, M. (1988) Biochem. J . 250, 95-101.

25. Heffetz, D., Bushkin, I., Dror, R., and Zick, Y. (1990) J . Biol . Chem. 265, 2896-2902.

26. Schmid, E., Hotz-Wagenblatt, A., Hack, V., and Droge, W. (1999) Faseb J . 13, 1491-1500.

27. Marin-Hincapie, M., and Garofalo, R. S. (1995) Endocrinology 136, 2357-2366.

28. Packer, L. (1998) Drug Metab. Rev. 30, 245-275.

29. Packer, L., Tritschler, H. J ., and Wessel, K. (1997) Free Rad. Biol. Med. 22, 359-379.

30. Rudich, A., Kozlovsky, N., Potashnik, R., and Bashan, N. (1997) Am. J . Physiol. 272, E935-E940.

31. Khanna, S., Roy, S., Packer, L., and Sen, C. K. (1999) Am. J . Physiol. 276, R1327-R1333.

32. Tirosh, O., Sen, C. K., Roy, S., Kobayashi, M. S., and Packer, L. (1999) Free Rad. Biol. Med. 26, 1418-1426. 
33. Tirosh, O., Sen, C. K., Roy, S., and Packer, L. (2000) Neuroscience $97,531-541$.

34. Sen, C. K., Tirosh, O., Roy, S., Kobayashi, M. S., and Packer, L. (1998) Biochem. Biophys. Res. Commun. 247, 223-228.

35. de Kok, A., and van Berkel, W. J . H. (1996) in Alpha-Keto Acid Dehydrogenase Complexes (Patel, M., Roche, T. E., and Harris, R. A., Eds.), pp. 53- 67, Brkhauser Verlag, Bazel.

36. Teichert, J ., Kern, J ., Tritschler, H. J ., Urlich, H., and Preiss, R. (1998) Intern. J . Clin. Pharmacol. Therap. 36, 625- 628.

37. Rosak, C., Hoffken, P., Baltes, W., Drinda, H., Ulrich, H., Tritschler, H. J ., Elze, M., and Blume, H. (1996) 5, 23-26.

38. Nemoto, S., Takeda, K., Yu, Z., Ferrans, V. J ., and Finkel, T. (2000) Mol. Cell. Biol. 20, 7311-7318.

39. J akubowski, W., and Bartosz, G. (2000) Cell Biol. Intern. 24, 757-760.

40. Nishikawa, T., Edelstein, D., Du, X. L., Yamagishi, S., Matsumura, T., Kaneda, Y., Yorek, M. A., Beebe, D., Oates, P. J ., Hammes, H. P., Giardino, I., and Brownlee, M. (2000) Nature 404, 787-790.

41. May, J . M., and de Haen, C. (1979) J . Biol. Chem. 254, 2214-2220.
42. Krieger-Brauer, H. I., Medda, P., and Kather, H. (2000) J . Biol . Chem. 275, 35920-35925.

43. Krieger-Brauer, H. I., and Kather, H. (1995) Biochem. J . 307, 543-548.

44. Krieger-Brauer, H. I., and Kather, H. (1995) Biochem. J . 307, 549-556.

45. Krieger-Brauer, H. I., Medda, P. K., Sattel, B., and Kather, H. (2000) J . Biol. Chem. 275, 2486-2490.

46. Krieger-Brauer, H. I., Medda, P. K., and Katther, H. (1997) J. Biol. Chem. 272, 10135-10143.

47. Han, D., Handelman, G., Marcocci, L., Sen, C. K., Roy, S., Kobuchi, H., Tritschler, H. J ., Flohe, L., and Packer, L. (1997) Biofactors 6, 321-338.

48. Denu, J. M., and Tanner, K. G. (1998) Biochemistry 37, 56335642.

49. Monteiro, H. P., and Stern, A. (1996) Fre Rad. Biol. Med. 21, 323-333.

50. Garant, M. J., Kole, S., Maksimova, E. M., and Bernier, M. (1999) Biochemistry 38, 5896-5904. 